\title{
苏联贸進科 学
}

\section{苏联冶金問題方面的科学研究工作}

\author{
И.П. 巴爾金院士
}

(苏联科学院副院长)

親愛的朋友們。

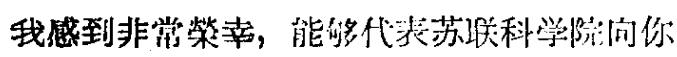

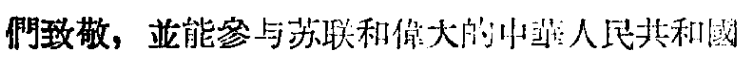

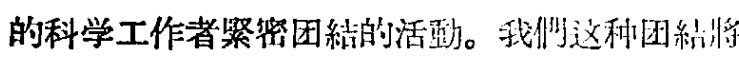
促進我們兩國科学的進步，因涌地將促進雨國相

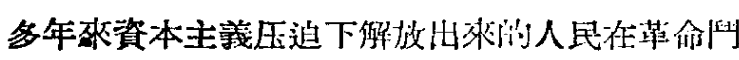
爭中共闹前進。

苏联已經存在將近 38 年了, 们中華人民共和 國在不久以前才尉㒭了成立 5 周年紀念日。自然， 在建設新生活的道路上我國已程照丁新多經驗,

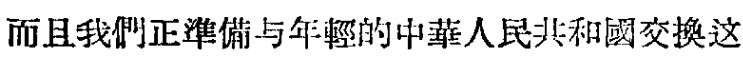
些經驗。我們兩個偉大的國家处在兄弟般的团絬

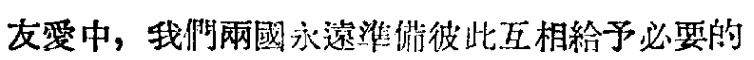

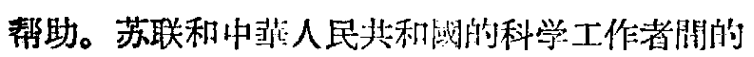
团結也应服从这仳任務。

我, 作篇一㑬冶金工作者, 今天想向大芜談 一談: 冶金部門科学所应喡决的一些閣題, 以及 在这方面苏联科学院对自己所提泏的一些任務。 在我的叙迌中, 我首先简短址叙述一下在我國革 命前与工業有關的科学研究工作的概况。

在鹤沙皇俄國㑐代，科学研究机關的地位是 非常低的。雖然, 在俄國荤命前的最後兩世紀 中, 在許多知識部門中筸經有过許多大学者, 給 世界的科学宝成帶來了不少非漟重大的貢献, 但 是科学發屡的條件在当時是非常差的。沙皇政府, 除了極少的例外情况外，不僅对科学的䝢展不給 予任何的重䙹, 而目甚至还常常对科学裴示猜疑, 恐怕它会䁰覆俄國其制制度的基礎。在这种情况

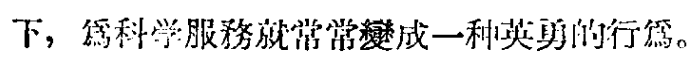

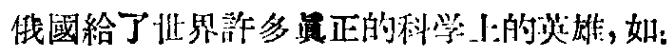

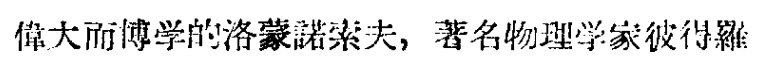
夫、㮙次、雅可比、列別揵夫和斯托列托夫，佔

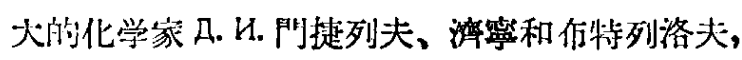
偉大的生理学家謝切諾夫和巴甫洛夫等。但是在

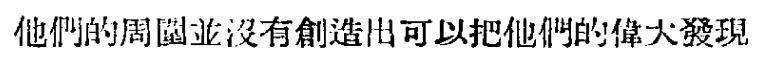
用於实際生活中去的條件，也沼有條件組織起科 学团体, 以便更廣泛地發展这些第他們所㷋了 的科学原理。

整個科学的觉工作在很長的结寺間內只是集中 在科学院裹。後來出现了第一批大学、專科学 校、科学团体。然而这些僅造沙滥中極小塊的称 洲, 既稀少而彼此文相隔很遠。科学研究工作只 在極少数高等学校和工澈的实睑豈裹進行。

俄國的工業在很大程度上掌握在外國資本家

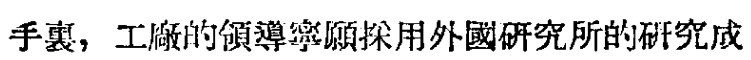
果, 这些外國的研究所在当時發袈得很快並且攡 有强有力的研究人材。这可以拿美國的碳業局和 德國的威㟲皇综研究所等國立机構作䍃例子。此 外, 在外國还有很多私立研究所, 而在俄國則非 常少有这种情况。

苏維埃政权与其他政权不同，从存在的第一 天起，在建設世界上第一個社会主義䂥会的事業 中, 就吸取了科学的制助。1918年B.И. 列路懒定 了一個科学技術工作計劃草染, 其中最重大的具 有全國意蜜的研究工作都委託科学院進行。在革 命嶰科学院份沼有一個科学研究所, 只有五倜不

* 本交是作者於1955年 6 月 3 日在中國科学院学 部成让大会上所作的赫占。
7 月号
利・学邀

- 75 - 
大的实擥室，而在苏維埃政权的年代中建立了約 60 個科学研究所, 它們都是苏联各做方面尃業科 学研究机閶網中的主要研究机構。在各加盟共和 國成立了科学院，在距離全苏科学中心較遠的較 大地區成立了苏联科学院的分院。在各部的領導 下有由專業科学研究所、研究站、研究室以及其 他研究机關組成的很大的研究絵, 这些机關在苏 联國民經源墢展中起着重大作用。工廠的中心試 驗室在上万的工做企業中進行着科学研究工作。 在浬等学校中繼續進行着大量研究工作, 其規模 是革命前完全無法比擬的。

当然，建立这漛包程万象的科学研究机閣絧 是一個很艰巨的任務, 住管如此, 它还是很快地很 順利地被解决了。科学的种子播种後需要有很長 時間于能得到丰碩的果实。很幸運的是，我們找 到一部分老敉授來做新建的研究所的勝任的領導 人和大量青年科学工作幹部的培养者。培养这些 幹部虺比培养工倣幹部困难, 因第在科学工作中 很少有固定的工作方式、重複性和某种定型, 这 訾篅要個人最大的創造主動性。

現在黑色冶金業的科学研究工作網可分永三 部分:（1）工确的中心試驗室（2）以黑色治金

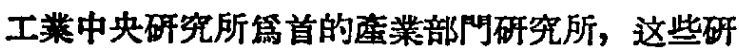
究所是由苏联黑色冶金工業部領導的; (3) 苏联 科学院治金研究所和加盟共和國科学院以及苏联 科学院分院的有關各所。大部分地方性研究所所 研究的題目是和它工作的地區的特點有關的。

工做实驗室除去检查現有的生産外，也進行 研究工作, 这些研究工作首先是对体厰生犮意 的，当然也对同類的企業有意義的。此外，工 筑笑驗空还是培美幹部的重要学校。偉大的冶金 学家之一，已故的 B.E.格鲁姆-格确日馬伊洛数

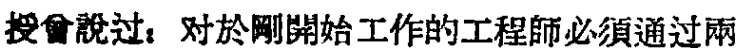

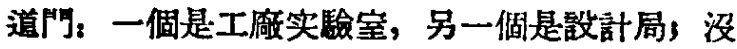
有烡他的路。在培养工程師幹部時, 特別是在科 学研究所的工作中，我狮努力道循这個原則。

其次，以莫斯科的中央研究所第首的、在黑色 治金工業部領導下的各科学研究所，它們的任歌 是研究对所有工廠或对整個一系列工故具有重大 意義的事物，这些事物是在实際中需姴银迅速地 運用上去或者是正在被運用中的。有時，在这些研 究所中也進行理論性的重大研究工作。有些研究
所不僅有实驗空設牉，而且还待小型的实驗工激，

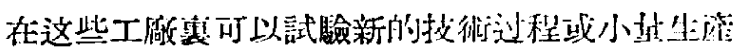

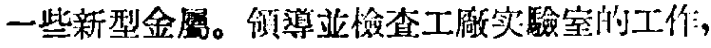
在工故中推廣新技術亚總絬工倨的經驗，䍐获联 黑色冶金工業部中央科学研究所的工作之一。近

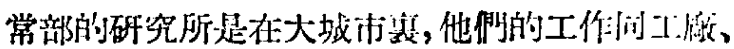
科学院的研究所和演等学校的試驗空都有职系。

最後, 科学院, 或这正碓地說是它的研究所, 加盟共和國科学院的研究所和分院的研究所, 它

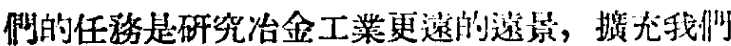
關於治金过程物理学化学基礎的知㰴议、研究金

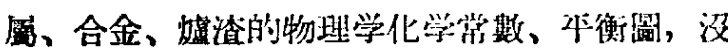
有这些就不可能对生噍过程做科学的分析, 不订

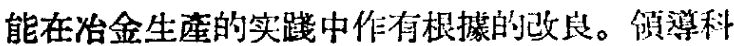
学院研究所中的研究窒的都是科学院的院士和通 訊院士。

自然，不能只从字面上桃了解这种分工。時 常在我們的工做試驗室中，尤其是在部的研究所 中進行一些具有重大科学甞淁的研究工作, 而且

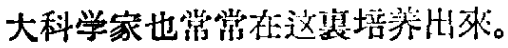

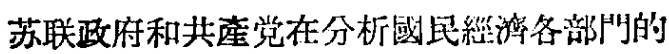
工作中，从來也不曾忘了科学，不会扎科学放到 一边不進行分析。我們科学工作者經常变到党和

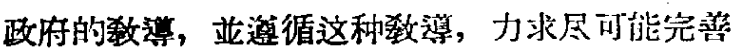
地第人民服務。最近我們党的十九次代永大会向

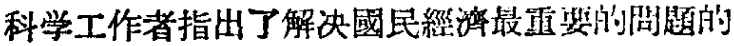

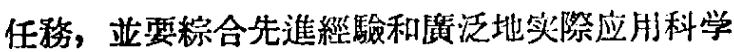
上的新發現。同時，党的十九次代表大会还碓立 了必要的均衡, 沒有这种均衡科学本身既不能有 应有的狆展, 也不可能对生的改良和增長起应 有的影响。这种均衡就在於同时摡研究各知識部 門中的理論問題（沒有这种研究科学本身就不能 發展), 也策固科学与生産間的联系（沒有这种联 系就不能促進最大限度的技術的進步和生增的增 長)。

根據这個指示編制了苏联科学的究机丵的全

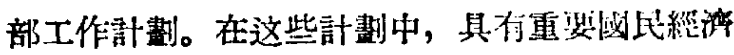
意義的重大問題和保証科学技術進一步發罢的理: 諭問題都佔有决定性的地位。此外，还制定了推 盧研究成果的具体計劃，这就是使这些成果得到 殿泛实際应用的計踾。

目前，在冶金部門中，在我們面前究賞偖那 
些主装科学閏題呢? 下晒我打算国答一下这湖問 題。

金镯是所有各种技術的基本建設材料，其中

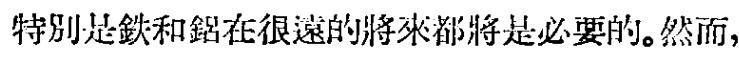
含有这些金屬的原料的隶源却日往筫泛了。到現 在䉆此，冶金業做第一閏科学和技術，踓然外部

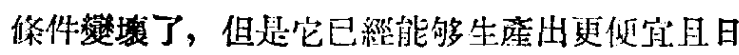

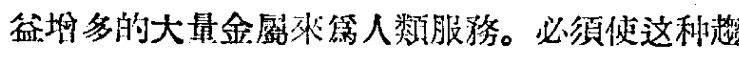

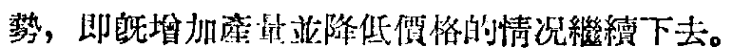
冶金科学的基本任狢助在於此。許多人認篤这是 所謂应用科学的任務, 是所謂工答学的任務, 其 实，在科学之䦭亚沒有这种喿限，什密地方固執 这种界限, 邦婰就是將科学有意識地脫離了生活。

一般地談到科学洔, 如果不將它分䉆純科学 和应用科学, 則科学应該能回答兩個基本問題, 即: 某一种現象敀惁樣進行, 它第什突以这栐或 那样的方式進行。因此，可以說屬於自然科学和 技術科学的全部科学都有雨部分一一試驗部分和 理諭部分。在大多数科学中，沙有試驗，理諭不 可能得到应有的發展, 而且, 試驗对於証实某和 理諭結論也是必需的。在应用科学中，試驗工作 比理論工作多; 在純科学中, 由於各門科学种類 不同，試驗方法的被应用程度也各不相同。

在一百年以前，冶金学还被称第一种技㙯。

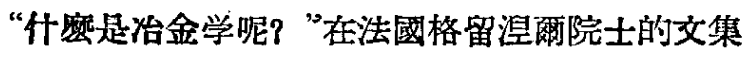
中宾着这㥞的定義: “冶金学是慗造金屬的一种

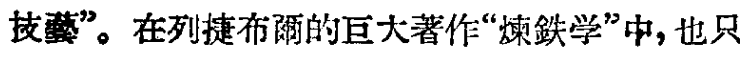
描逝了生產鉄時所進行的各种过程，亚沒有特別 解糞它們進行的次序及速度。从著名的法國科学 家勤・沙捷里耶開始，他的追随者A.A.巴依 柯 夫院士，B.E。格魯姐・格爾日馬伊洛、M.A.巴甫 洛夫，第了要解釋冶金过程的規律，引用了所謂 的勒・沙捷里耶規律，这個規律是这樣解釋冶金 过程的方向的, 即: 在升高温度時, 進行着吸熱 过程, 在降低温度時, 發生放熱反应。也就是锐 整個系統是抗拒着温度綎化的。这個規律只有定 性的意義，在它的基礎上不能捉供任何定量的結 諭。

最近的冶金学敉程已經用物理化学數㨜來闻 述冶金过程了。最初在物理化学及熱力学基礎上 隶解釋冶金过程的在德國有申克授，在我國有 M.M. 卡爾納鸟霍夫院士。这襄还不能不提到著
名的德國巴烏克洛烏敎授的關於治金过积理論閣 題的著作。

然而, 由於最近科学特别是物理学進一步的 發展, 那些在 10-15 年以前还是完全足够的理 諭論幏，現在已維成完全不充分了。对於物質絬 棈、分子、原子、離子、電子等的更潹入了解, 使我們不能不重新審查在这方面的部多概念了。

冶金学方面的科学試驗特别困难, 这览因琈 它涉及高温範園的工作。这也是冶金学在理諭剧 虹直上落後的原因。通常, 实践總是超过理諭。

如果把冶金科学分点兩话基本部分, 即: 冶 金学本身(研究从喛石中提煉金屬)和金屬学, 或 更正確地說，是金風物理学（如果把金歷学看做 類似於貨物鑑定学或材料检驗学, 抽就是低估了 这門科学的实質, 並且給了它不正確的定義), 丼 末, 和冶金学相比, 应用金成科学新成破的䦌題 是更多地屬於金屬物理学的。

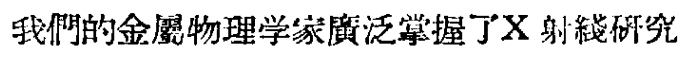
方法，他們能够研究晶体結棈、晶体中综于的分 作，有時甚至还能測定原子間力(絬合力)。品然 这工作有時还不能適应实際的慗求, 但是既 已找到了途徑, 掌握了方法, 其成果自然会大大 增多。最近出現了一种新的研究工具一一即闹位 素(稳定的，並具存不同的牛委期的)的应朋。

我國科学家在金犀物理学中这一方面的矼究 是國外非常重頑的。庫隬久莫夫院士及其学派， 卡納別耶夫斯基、科馬西等的工作在國外被㕍泛 地引証。H. C. 庫爾納科夫院士学派, Г. Г. 烏拉佐 夫和他們的同事㑚所研究的平衡圖在國外也被 展泛地引用着。在这方面我們还可以指出馬烏耶 爾、塔瑪洞、古德列蒙及其他德國冶金学数授的 卓越工作。

在冶金学本身，即在研究並確定冶金过程規 律方面的情况就不是这樣了。㙷然，在这方面我 們的研究工作是很不够的，在这震和在金閔物理 学問題上一樣, 同樣可以運用物質結構的 新 知 識。火法冶金过程提出了在容温和反应速度很高 的物理学化学狀况下傩生的複雜現象。冶金学者 的基本努力方向就是獲得过程的最高速度，㷅好 地利用原料和然料，得到最大的設借生产䇣，佔 使有可能, 則还姴獲得連繢的过程。

鹪要控制这類过程, 对於大部分在多相介啠

\section{7 月号}

科学遡報 


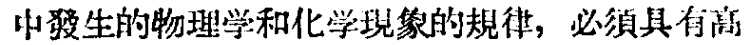

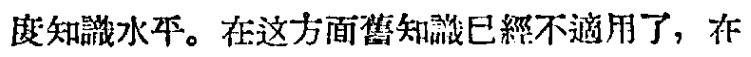
实驗空佟作下研究冶金反应过程動力学所得到的

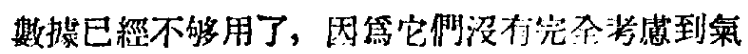
体動力学的規律和不同体積、外形及狀態的顆粒 狀和受籍性物体的流動規律。这些是屬於䵖嘘熔 化的理論的, 以及屬於反射嘘揢煉等的。必須更 多地在模型中及用其他方法, 如用同位溸方法, 研究在高嘘中、帶水套的嘘中及其他烧中的材料 和氣体不嘘內的運動力学。

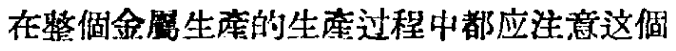
問題。如果对於在多相條件下進行的过程的反应 動力学还不清楚, 就不可能有把握地选擇这种或

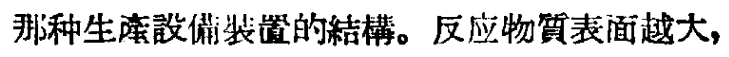
則一切多相过程進行得越快, 而实際上第保証过 程進行得更匀調，我們將烧料在未入堵之前先燒 結，因而丢失了基本的優點一大的表面。氣体 沿恠子截面的分佈和控制这种分佈的問題还汥有 充分地研究，也还缺乏閣於这個規律的清楚的概 念。

我們还沒有用岩石学方法研究过獲得嘴料

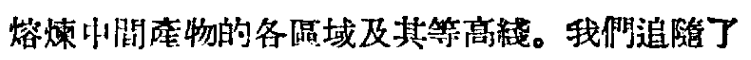

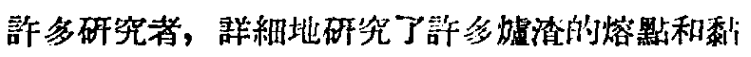

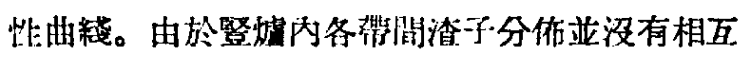
閣係, 它們仍然保留原來的狀態, 而固態、受範 性、液態物料的運動也来會被研究过, 过程的

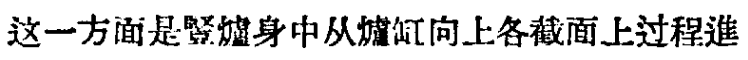
行速度的指標。这個問題要求我們測定一采列的 物理学化学賞数, 擬定一系列的儀器、模型和方 法。總的任務就是使分子間的力加入到过程中去, 並最大限度地利用这种力。除此之外, 还有原子 力、離子力、電子力, 这些力的作用和意義还 未完全清楚, 但無疑的, 所有过程中都存在着这

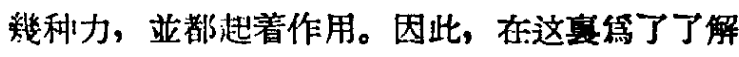
过程蕜控制这些过程, 就需要利用物理科学。

重要的缺點在於在加速冶煉过程、減低物料 消耗和提高应品質量方面, 冶金学家只利用了潞 度和反应物翼濃度的繸化; 只在很小的程度上探 取物筫的压力效化和利用表酒能來解决 这些問

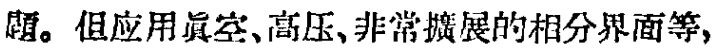
还可以保㩆有閣备过程更快更完全地進行。

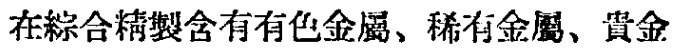

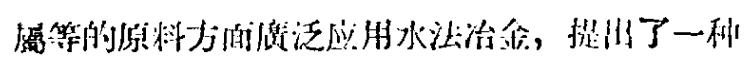

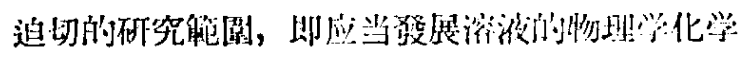

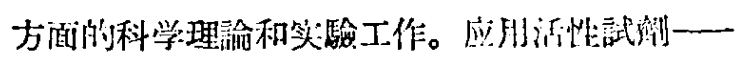

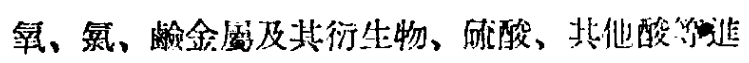

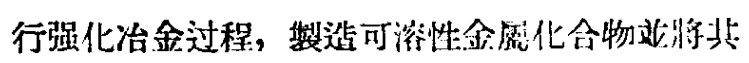
选擇性分離成純金屬或金屬化合物狀態，这些工 作都因理論凟料皘累不足及泎多反应未无分研究 等, 受到了阻碍。

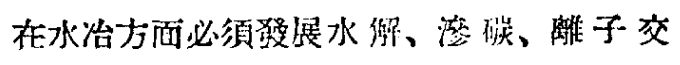
換、吸着現象、金展有机化合物的形成及其它过 程的理諭砄究。

在冶金学山熱交換的碑究还相当落後。熱 $\mathrm{x}$.

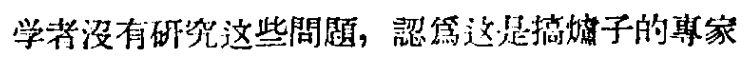
及冶金專家的事。而打搹嘘子及治金的，踓然标

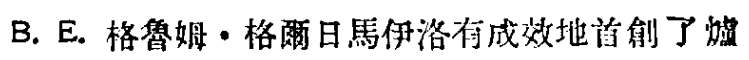
子計算方面的理諭，而不是根掉經驗，但是招这 方面的工作仍很不足。我們必须㓣浩超速加熱的

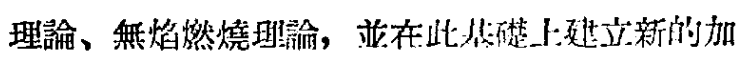
熱設俳;

应該注意，如果有通器的保件下，在火焇和

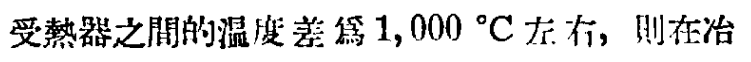
金嘘中这种美常不能超过 $500^{\circ} \mathrm{C}$, 因之, 所有的

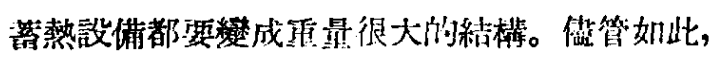

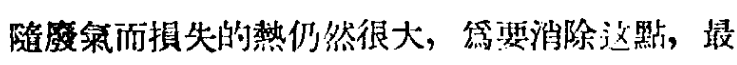
有效的方法应該是快速加熱和话速熱循環。这樣 才能炛於舆洔間的輻射損失熱量。

加熱本身不应以对流方式進行, 而应以輻射 方式，即利用紅外綫，它不䍃妥熱物休表面所限 制, 而与高頻加熱相似, 可以穿入到深处, 蓝且 使物体迅速加熱, 此時不会在無熱物体装面和中 心之間造成倠害的熱应力。

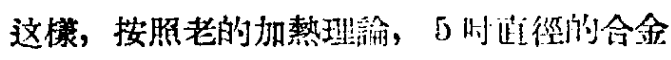

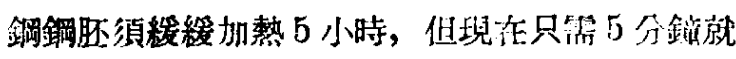
能將这种胚子加熱了。快速秃熱技衍篮要大煋理

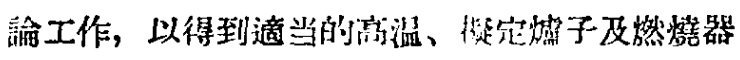
的結構, 並决定最值效的应肘少法。

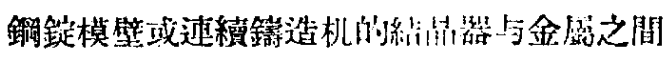
的熱过程也完全滩伯研究过琙南研究得很不够。

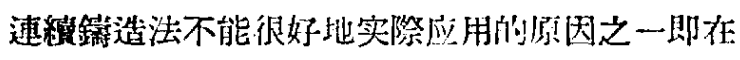

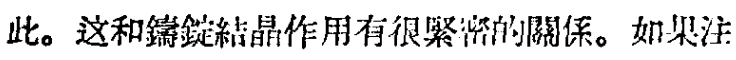
意到鉱錠理論研究的情况，則可知枝近50 年內,

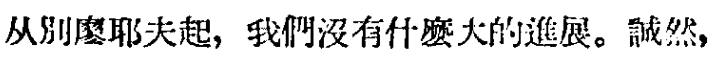




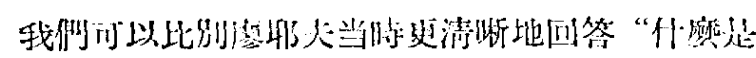

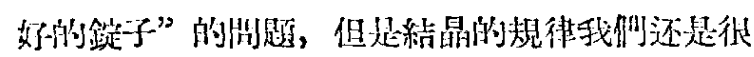
模料，我們还不知道如何才能得到好的鉆子。可 能必須从較裳的地方着手研究这湖問題, 並以比

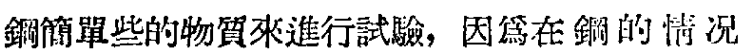
下，温度較高，相成分在凝固过程中有戀化，且 現像本身進行得非常快。必須在結晶过程中以各 种頻举菂振渣進行大量的团难的試驗——不同的

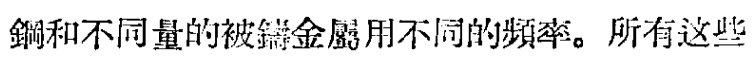
間題都需恐研究。

可以說, 如努从理論上来放明治金过程, 最 国难的是相䋛進行得非常快的，例如上耐已蓝的

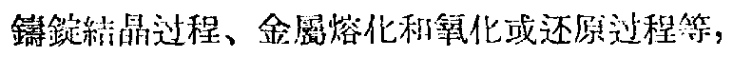

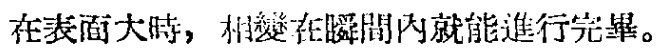

在使用新法錦接使金䖯結合特，这些因嗉最 䮧集中, 雖然这湖过程看承很简毠，但理論上却 非常椱雜, 还須繼縜研究。在我们科学院治金研 究所異有一個部閒是研究錦接的, 它的任務仙括

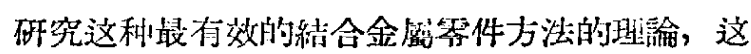
种方法在实際上是很有成效的，但在理論上研究 得还不够, 因此在進行中有時还有很大部美, 需 要㐿出高伦價來改正。

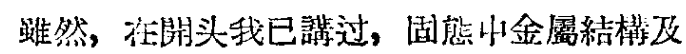
其性質的金屬物坦学原理比較清楚了，但这只能 了㙰第相对的，而不焂絕对的。金䐂物理学方面

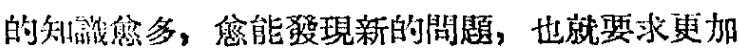

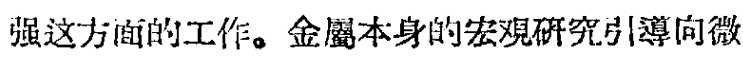
覌研究，而微观砋究文將冶金学和金墽物理学联 系起來亚使之相接近。

烄近，科学.上有很多新方法用於研究过程 中, 一而位素， $\beta$ 射䋓、 $\gamma$ 射綫、電子顯微鏡、 電子衍射儀、分修本領很高的普通的和 $\mathrm{X}$ 䋃的光 譜儀, 所有这些最新裝備起來的武器, 給我們認 識物听捉供了新的可能性, 在我們这門学科中, 就是去認識金屬。这些可能性使我們的工作更容 易,䓦壁了我們工作的战綫，要求我們很多的研究 工作者將自己的力量集中在这個方面。如果现在 不考虑这些，則將失去時間，而時間是一去不復 返的。

在金鞨压力加工方面，必須進一步發展一般 理沙和個则加工類型的特殊理論, 其中有压延理

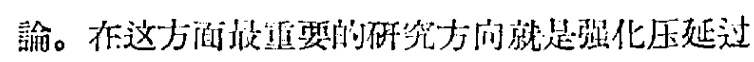

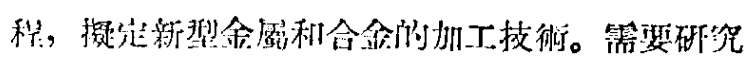

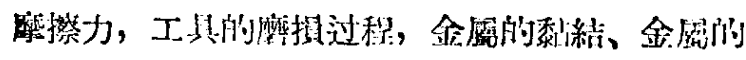

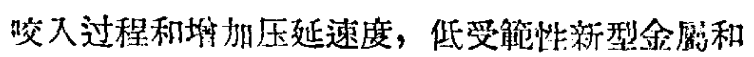
合金的加工條件。

最後，在金閩中最主要的是在各种温滦下的

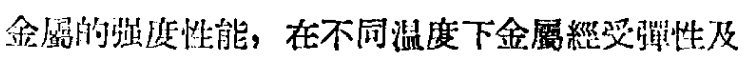
受触性形継的能力。高温、高压技術或低温滈压

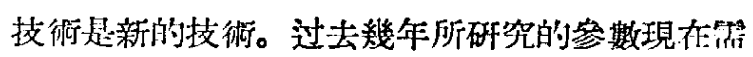
要援充。

如將上面所述的綜合一下，則目前在冶金方

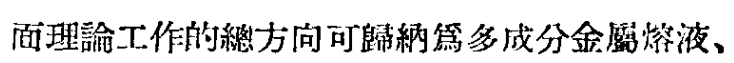
柔化物、其他化合物的最重要的性質的䂰究（如 熔點、熔融熱、黏度、溥電性、表矿張力等), 測 定熱化学數值, 測定各种反应和过程的激活能、 原子間的結合能，在生趛條件下各种反应和过程 的動力学。应根據所得的數㨜, 建立强化現有过 程和新的更完善的治金过程的理䄖步礎。

在氣体、液体、固体運動方面的任務是: 研 究在多相及均質 (單相) 介啠山，在站积進行赔 度很小与很大時順流与逆流力向的滥動規律和热 交換。

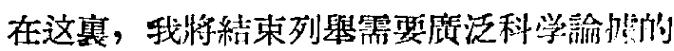

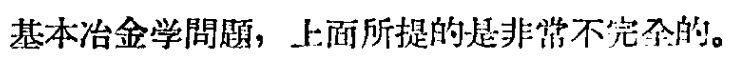

当科学与生陸年固地結合在一起時, 这些間 題才能暊利地解决。我梁信, 由於科学与生䔞的 結合, 对网方面是同裳有利的, 工業技術很久以來 对科学發展起着重大影响。藉助於解决当前生潼 問題 (水力学、空氣動力学、熱机械理渝) 的技 衍, 整個科学各部門建立起來並發展赽來了。在 各個科学㓱造方面, 实踐常常䞨过了理諭。恕記 任恩格斯的一句話: 佩若社會上有了一种技術上 的需要, 那就比十個大学还更能推動科学前進。 这襄, 最主要之點还在於生产实際, 它每天特 許多新事实, 当科学家得到通往这些事实的門徑 的時侯, 他們就在自己的科学部門中学進一步的 前進獲得了新的堡壘。

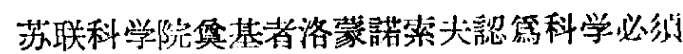

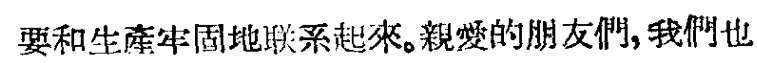
将追隨这個榜樣。在科学上人們的任務就是使科 学接近於解决最重要的國民經沙問題, 並由此提

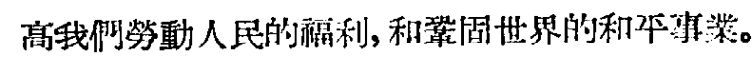

〔王景辒譯〕
7 月号
科学䖝報 